\title{
Induction Generators for Direct-Drive Wind Turbines
}

\author{
Henriksen, Matthew Lee; Jensen, Bogi Bech
}

Published in:

Proceedings of IEEE International Electric Machines and Drives Conference

Link to article, DOI:

10.1109/IEMDC.2011.5994759

Publication date:

2011

Link back to DTU Orbit

\section{Citation (APA):}

Henriksen, M. L., \& Jensen, B. B. (2011). Induction Generators for Direct-Drive Wind Turbines. In Proceedings of IEEE International Electric Machines and Drives Conference IEEE.

https://doi.org/10.1109/IEMDC.2011.5994759

\section{General rights}

Copyright and moral rights for the publications made accessible in the public portal are retained by the authors and/or other copyright owners and it is a condition of accessing publications that users recognise and abide by the legal requirements associated with these rights.

- Users may download and print one copy of any publication from the public portal for the purpose of private study or research.

- You may not further distribute the material or use it for any profit-making activity or commercial gain

- You may freely distribute the URL identifying the publication in the public portal

If you believe that this document breaches copyright please contact us providing details, and we will remove access to the work immediately and investigate your claim. 


\title{
Induction Generators for Direct-Drive Wind Turbines
}

\author{
Matthew Henriksen, Bogi Bech Jensen* \\ Center for Electric Technology, Department of Electrical Engineering \\ Technical University of Denmark \\ 2800 Lyngby, Denmark \\ *Email: bbj@elektro.dtu.dk
}

\begin{abstract}
This paper considers the use of a squirrel cage induction generator for a direct-drive wind turbine. Advantages of this topology include a simple/rugged construction, and no need for permanent magnets. A major focus of this paper is the choice of an appropriate pole number. An iterative, analytical design process is employed to create generators of different pole numbers for comparison, with static 2-D finite element analysis used for verification. It is shown that increasing the pole number has the effects of reducing the required core material, reducing the power factor, increasing the leakage reactance, and increasing the efficiency.
\end{abstract}

\section{INTRODUCTION}

$\mathrm{D}$ IRECT-drive wind turbines have been noted to be a trend in the wind turbine industry. The generators are heavier and more expensive, but this is ideally offset by the benefits of removing the gearbox from the construction. Permanent magnet generators have been found suitable for this application, but the unpredictable costs and availability of rare earth metals is a deterrent. The wind turbine configuration being considered in this paper is an outer-rotor direct-drive induction generator, connected to a full-power converter. Due to the lack of permanent magnets or salient poles, there is potential for a rugged, competitive design. Table I lists the ratings used for this study.

TABLE I

GENERATOR RATINGS

\begin{tabular}{lll}
\hline Parameter & Symbol & Value \\
\hline Rated power & $P_{\text {out }}$ & $3 \mathrm{MW}$ \\
Rated voltage & $V_{L L}$ & $690 \mathrm{~V}$ \\
Rated speed & $n_{m}$ & $15 \mathrm{rpm}$ \\
\hline
\end{tabular}

\section{ARgument FOR INDUCTION GENERATORS FOR DiRECT-DRIVE WIND TURBINES}

\section{A. Reliability of Direct-Drive Wind Turbines}

A Comparison of direct-drive and gear-driven wind turbine generators has been performed [1], where Polinder et al. demonstrated that direct-drive wind turbine generators tend to be heavier and more expensive than wind turbine generators used with gearboxes. The work performed by Polinder et
TABLE II

NOMENCLATURE

\begin{tabular}{ll}
\hline Symbol & Description \\
\hline$\phi_{p}$ & Peak flux per pole \\
$\phi_{c b}$ & Peak coreback flux \\
$L$ & Axial length of machine \\
$D_{s}$ & Outer diameter of stator \\
$p$ & Number of pole pairs \\
$A_{c b}$ & Coreback cross-sectional area \\
$d_{c b}$ & Coreback depth \\
$L_{s l o t}$ & 1-phase winding length in slot \\
$L_{e n d}$ & 1-phase end winding length \\
$\tau_{p}$ & Pole pitch \\
$\tau_{s s}, \tau_{s r}$ & Slot pitch (stator, rotor) \\
$d_{s s}, d_{s r}$ & Slot depth (stator, rotor) \\
$q_{s}$ & Stator slots per pole per phase \\
$S_{s s}$ & Useful cross-sectional area of stator slot \\
$S_{c o n d}$ & Useful cross-sectional area of stator conductor \\
$S_{b a r}$ & Useful cross-sectional area of rotor slot \\
$k_{s r}$ & Effective turns ratio \\
$k_{p}$ & Pitch fraction \\
$k_{w}$ & Winding factor \\
$N_{s}$ & Series turns per phase \\
$l_{g e}$ & Effective length of air gap \\
$L_{e}$ & Effective length of machine \\
$\lambda_{s l o t}$ & Slot permeance factor \\
\hline
\end{tabular}

al. also underlines the fact that modern wind turbines using doubly-fed induction generators are satisfactory with regard to their cost and size, and that the benefit of moving towards direct-drive generators can only come from increased reliability. However, there is some evidence that the current trend toward the use of direct-drive wind turbines is not giving the expected increase in wind turbine reliability.

Studies have shown that the failure rates of the generator and power electronics are higher for direct-drive wind turbines than for those with gearboxes [2],[3]. Based on observed component failure rates, a techno-economic comparison has shown that direct-drive machines can produce a higher amount of energy per annum, but this is not typically enough to offset the increased failure rate and cost of the generator. It is also found that a reduction in cost of nearly $50 \%$ is required for the present direct-drive wind turbines to be competitive from a revenue standpoint [4]. In light of this, one factor that bears considering is the present topology of direct-drive wind turbines. Electrically-excited synchronous generators have been used for several generations of direct-drive wind 
turbines. The authors of this paper suggest that a squirrel cage induction generator reasons to exhibit higher reliability than an electrically-excited synchronous generator. The total number of required components will be reduced, since there is no need to provide DC excitation for the field poles. Permanent magnet synchronous generators have also been selected for many of the latest direct-drive designs. Increased reliability should be achieved by these new direct-drive wind turbines, but a squirrel cage induction generator could make the reliablity better still. The nature of synchronous operation implies that every change in rotor torque will be directly transmitted to the power converter in the form of a power fluctuation. Since an induction machine operates with some slip, there is a damping effect which will partially smooth such fluctuations.

\section{B. Rare Earth Supply}

Neodymium iron boron $(\mathrm{NdFeB})$ has become the leading magnet for rotating machine applications. Neodymium is one of 17 metals known as 'rare earths', which are difficult to mine and separate due to their chemical similarity. While $\mathrm{NdFeB}$ magnets are powerful, their temperature performance is not satisfactory for many rotating machine applications, such as in electric vehicles or wind turbines. To make the magnets more suitable in this regard, they are alloyed with a second rare earth metal, dysprosium. The amount of dysprosium required is much lower than the amount of neodymium, but dysprosium is significantly more rare and expensive than neodymium [6].

Today the entire rare earth supply chain depends on China, where almost all of the world's rare earths are mined and processed [7]. In the last decade, China's demand of products which require rare earth metals has risen drastically, and China has begun reducing rare earth exports significantly. China is taking measures to consolidate mines, shut down illegal mines, control smuggling, estimate exactly what their rare earth resources and demands are, and decide what the cost of metals such as neodymium and dysprosium should be. In the near future there will be several viable sources of neodymium coming onstream outside of China. There is also a great deal of optimism that a viable producer of dysprosium will soon come onstream as well [8]. These events, will mark the rebirth of the rare earth supply chain outside of China. Until then, whatever China decides following their appraisal of the rare earth industry will determine the price and availability of rare earth metals. Today, there is a great deal of uncertainty about the future price of neodymium. Additionally, the world's supply of dysprosium can't be guaranteed. China has said that their reserves may be depleted in 5-25 years [6]. It is yet to be seen what the suppliers outside China are capable of, but it is possible that dysprosium will continue to be more rare and more expensive in the coming years. Therefore, the fact that a direct-drive induction generator requires no rare earth metals presents an advantage, considering the unpredictable future of the rare earth supply chain.

\section{GENERATOR DESIGN}

\section{A. Design Restrictions}

In the interest of creating initial designs which are comparable to one another, some restrictions are stated. It should be stressed that these restrictions are only put in place to facilitate the process of creating some basic designs, and that these values are not suggested to be optimal. Table III gives the restrictions for this preliminary study.

TABLE III

CHOSEN DESIGN RESTRICTIONS

\begin{tabular}{lll}
\hline Parameter & Symbol & Value \\
\hline Peak air gap flux density & $\hat{B}_{g}$ & $0.9 \mathrm{~T}$ \\
Peak coreback flux density & $\hat{B}_{c b}$ & $1.8 \mathrm{~T}$ \\
Stator current density & $J_{1}$ & $3.5 \mathrm{~A} / \mathrm{mm}^{2}$ \\
Outer diameter of rotor & $D_{r}$ & $5 \mathrm{~m}$ \\
Air gap length & $l_{g}$ & $0.001 \times D_{s}$ \\
Number of stator slots & $Q_{s}$ & 180 \\
Number of rotor slots & $Q_{r}$ & 240 \\
Ratio of tooth to slot width & $a$ & 1 \\
Rotor slot depth & $d_{s r}$ & $5 \times \tau_{s r}$ \\
Slot opening width & $b_{1}$ & $0.5 \times \tau_{s s, s r}$ \\
Slot opening depth & $d_{1}$ & $0.1 \times d_{s s, s r}$ \\
Conductors per stator slot & $z_{q}$ & 3 \\
Stator slot fill factor & $k_{s f}$ & 0.6 \\
Number of phases & $m$ & 3 \\
\hline
\end{tabular}

\section{B. Stator and Rotor Geometry}

As the number of stator and rotor slots has already been chosen, the design process begins by choosing the pole number, the outer diameter of the stator, and the axial length. The peak flux per pole is calculated for a peak fundamental frequency air gap flux density of 0.9T (1). In turn, the value of $\Phi_{p}$ is used to calculate the coreback depth required for a peak coreback flux density of 1.8T (2-4). The flux per pole depends inversely on the number of poles, and this results in the need for larger corebacks for machines with small pole numbers.

$$
\begin{aligned}
\Phi_{p} & =\frac{\hat{B}_{g} L D_{s}}{p} \\
\Phi_{c b} & =\frac{\Phi_{p}}{2} \\
A_{c b} & =\frac{\Phi_{c b}}{\hat{B}_{c b}} \\
d_{c b} & =\frac{A_{c b}}{L}
\end{aligned}
$$

Regarding the slot dimensions for the rotor and stator, the ratio of tooth width to slot width is 1 , meaning that the slots and teeth have the same width. The rotor resistance should be as low as possible, in order to minimize losses. This suggests deep slots, giving plenty of cross-sectional area for the rotor bars. Therefore the rotor slot depth is chosen to always be five times the slot width, which the authors consider to be relatively deep. The stator slot depth is initially chosen to be between three and five times the slot width, but this value is 


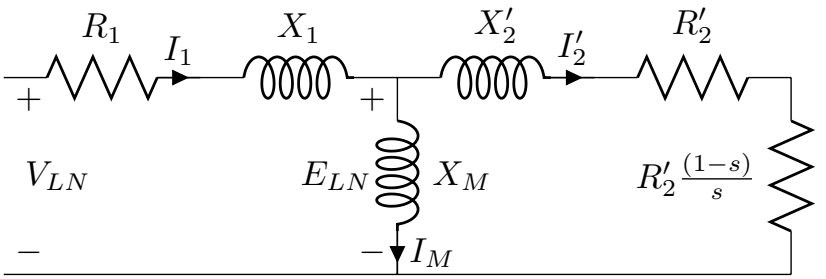

Fig. 1. Single-phase induction machine equivalent circuit

adjusted throughout the design process in order to affect the current density. The length of the air gap is always $0.1 \%$ of the air gap diameter for the designs being created in this study, which is a consideration related to manufacturing tolerances [9].

At this point the stator and rotor dimensions have all been established. The outer diameter of the machine is obtained based on the initial values of the stator diameter, the air gap length, the slot depths, and the coreback depth. The stator diameter is adjusted as required in order to obtain an outer diameter $\left(D_{r}\right)$ of five meters.

\section{Equivalent Circuit Parameters}

After selecting the stator and rotor geometry, the process of deriving the equivalent circuit parameters begins. Figure 1 shows the employed form of the equivalent circuit, which is considered in the motor convention.

1) Stator Resistance: The resistance of one stator winding is estimated based on its length, cross-sectional area, and conductivity. The coil length is partially in the slots and partially in the end region. First, the length in the slots for one phase is calculated (5). Concerning the end winding length, each end turn is assumed to be 1.5 times the length of a pole pitch, for a full-pitch winding [10]. From the length of a single end turn, the number of conductors per slot, the number of slots per pole per phase, and the number of poles, the perphase end winding length can be estimated (6). Since the stator slot fill factor of 0.6 has been stated, $60 \%$ of the stator slot area is assumed to be copper. Then for $z_{q}$ conductors in a slot, the conductor cross-sectional area is found (7), and finally the stator resistance can be estimated (8).

$$
\begin{aligned}
L_{\text {slot }} & =\frac{Q_{s} z_{q} L}{m} \\
L_{\text {end }} & =1.5 \tau_{p} z_{q} q_{s} 2 p \\
S_{\text {cond }} & =\frac{k_{s f} S_{s s}}{z_{q}} \\
R_{1} & =\frac{\left(L_{\text {slot }}+L_{e w}\right)}{S_{\text {cond }} \sigma_{c u}}
\end{aligned}
$$

2) Rotor Resistance: Squirrel cage rotor resistance is determined by contributions from the bars and the end ring [11]. Calculation of the resistance of a single rotor bar is straightforward (9). A single section of the end ring is assumed to have length equal to a pole pitch, and cross sectional area five times that of a rotor bar. With these dimensions, the estimated resistance of an end ring segment can be found (10). The rotor resistance can then be calculated, and it must be noted that the end ring's contribution to rotor resistance depends on the number of pole pairs (11). The equivalent turns ratio between stator and rotor must be calculated (12), and multiplication of the rotor resistance by this factor gives the rotor resistance as seen from the stator side (13).

$$
\begin{aligned}
R_{b a r} & =\frac{L}{S_{b a r} \sigma_{c u}} \\
R_{e r} & =\frac{\tau_{p}}{5 S_{b a r} \sigma_{c u}} \\
R_{2} & =R_{b a r}+\frac{R_{e r}}{2 \sin ^{2}\left(\pi \frac{p}{Q_{r}}\right)} \\
k_{s r} & =4 \frac{m}{Q_{r}} k_{w} N_{s}{ }^{2} \\
R_{2}^{\prime} & =k_{s r} R_{2}
\end{aligned}
$$

3) Magnetizing Inductance: The magnetizing inductance is calculated based on the geometry of the machine, as well as the winding arrangement [11]. This parameter has an important effect on the reactive power consumption of the generator. The inverse dependence on the pole number demonstrates the reduction in magnetizing reactance, and the increased need for magnetizing current which are observed as the pole number rises (14).

$$
L_{M}=\frac{3 L_{e} D_{s} \mu_{0}}{p^{2} \pi l_{g e}}\left(k_{w} N_{s}\right)^{2}
$$

4) Leakage Inductance: Three types of leakage inductance are considered in this study: slot leakage, zigzag leakage, and end winding leakage. Slot leakage occurs due to flux which follows a path across a slot rather than the intended path, which is across the air gap via the teeth and through the stator and rotor corebacks. The inductance associated with this leakage path is dependent on the permeance of the slot and the number of turns being linked by the slot leakage flux (15).

The slot permeance factor varies for different slot shapes [11]. Referring to Figure 2 for the rectangular, partially-closed slots being considered, the permeance factor is calculated based on the slot geometry (16). The slot leakage is calculated independently for the stator and rotor. Like the rotor resistance, The rotor slot leakage must be referred to the stator for use in the equivalent circuit.

Zigzag leakage is due to variations in MMF between rotor and stator teeth. It is proportional to the magnetizing inductance, and inversely proportional to the number of slots per pole, squared. Zigzag inductance is estimated independently for the rotor and stator (17 and 18), and the results are found from the stator perspective [12].

The end winding inductance is due to the magnetic path surrounding each end winding. It is well known to be a difficult inductance to estimate. An empirical expression from literature [12] is used for the estimation (19). The resulting value is recommended to be split equally between the stator 


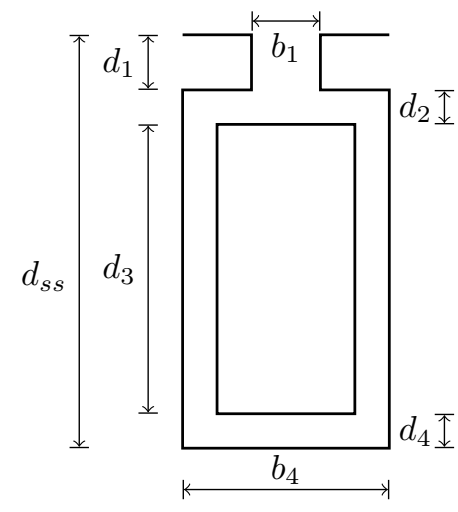

Fig. 2. Dimensions used for calculation of the slot permeance factor

and rotor leakage inductances, in the stator frame of reference. The values of stator and rotor leakage inductance used in the equivalent circuit are found as the sums of the individual leakage inductance components (20-21).

$$
\begin{aligned}
L_{l s} & =\mu_{0} L_{e} \frac{Q_{s}}{m} z_{q}^{2} \lambda_{\text {slot }} \\
\lambda_{\text {slot }} & =\frac{d_{1}}{b_{1}}+\frac{d_{2}}{b_{4}}+\frac{d_{3}}{3 b_{4}} \\
L_{l z s} & =\frac{\pi^{2}}{12} \frac{3 a-1}{5\left(m q_{s}\right)^{2}} L_{M} \\
L_{l z r} & =\frac{\pi^{2}}{12} \frac{3 a-1}{5\left(\frac{Q_{r}}{2 p}\right)^{2}} L_{M} \\
L_{l e} & =\left(k_{p}-.3\right) \frac{7 N_{s}^{2} m D_{s}}{2 \pi p^{2} 10^{6}} \\
L_{1} & =L_{l s s}+L_{l z s}+\frac{L_{l e}}{2} \\
L_{2}^{\prime} & =k_{s r} L_{l s r}+L_{l z r}+\frac{L_{l e}}{2}
\end{aligned}
$$

\section{Iterative Process}

Figure 3 demonstrates the cyclical nature of the design method. When the equivalent circuit parameters have been derived, it is possible to generate an output power vs. slip characteristic. Figure 5 shows several such characteristics, where observation reveals the value of slip which gives rated output power. Then, for this value of slip the stator current density and peak air gap flux density must be compared to the design restrictions $\left(3.5 \mathrm{~A} / \mathrm{mm}^{2}\right.$ and $0.9 \mathrm{~T}$, respectively). The machine geometry $\left(D_{s}, L, d_{s s}\right)$ must then be adjusted until these values are obtained. Adjustments in the geometry are reflected in the equivalent circuit parameters, and therefore a new operating slip is required. When the desired current density and air gap flux density are obtained for the value of slip giving rated output power, the design is finished.

\section{E. Verification with Finite Element Analysis}

Static 2-D simulations have been used to verify the induced stator voltage. The static $2 \mathrm{D}$ simulation is to correspond with

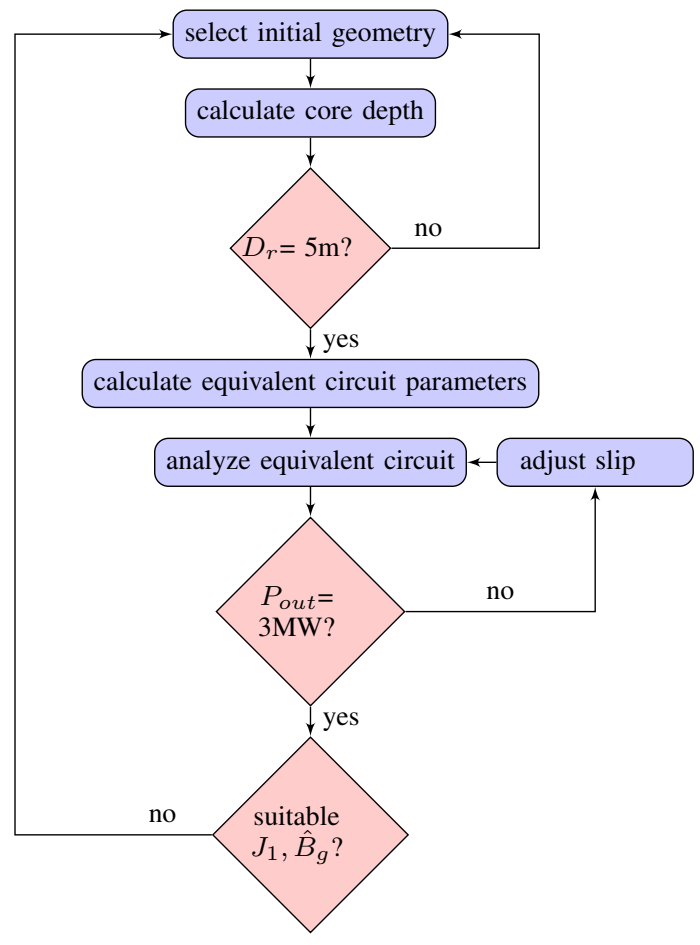

Fig. 3. Flow diagram describing design process

the instant of peak flux per pole, thereby verifying the peak induced voltage. At this moment the phase at the center of the pole has peak magnetizing current, and the two other phases carry one half of peak magnetizing current. This situation is duplicated in the finite element software by modeling the stator windings as current controlled, and setting them according to the magnetizing current found through analysis of the equivalent circuit. Then, with the static 2-D results for the flux linkage in the coil carrying peak current, the induced voltage can be estimated by multiplication with the stator electrical frequency. Since the analytical design has not considered the effects of saturation, one set of simulation results has been obtained using a linear material for the stator and rotor iron. A second set of simulations has been performed using laminations (M310-50A), and here saturation is accounted for. Table IV shows the comparison of results. When saturation is not considered, the voltage is overestimated by less than $10 \%$ in all cases. With saturation, the results are 10-15\% lower than the values found analytically. These results therefore agree with the analytical results, within a tolerance that is suitable for the early design process being described in this paper.

TABLE IV

RESULTS OF STATIC 2D SIMULATION

\begin{tabular}{lccc}
\hline & \multicolumn{3}{c}{$E_{L N}[\mathrm{~V}]$} \\
\cline { 2 - 4 } Poles & Analytical & FEA (Linear material) & FEA (M310-50A) \\
\hline 12 & 574.4 & 622.6 & 510.6 \\
20 & 546.4 & 563.0 & 479.1 \\
30 & 490.2 & 525.7 & 419.1 \\
\hline
\end{tabular}




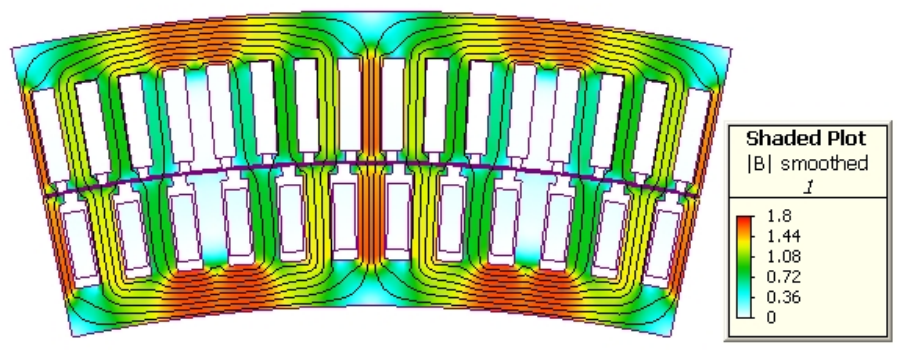

Fig. 4. Results of static 2D simulation for two poles of a 30-pole generator, indicating flux lines and flux density

\section{Comparison of Different Pole Numbers}

\section{A. Results}

Generators with pole numbers of 4, 6, 12, 20, 30, and 60 poles have been considered for this comparison. Figures 5 through 7 explain the results graphically. As expected, the active mass decreases as the pole number increases. The required copper is basically not affected, and this reduction in mass is largely due to the previously-mentioned reduction in required coreback depth (1-4). Another factor contributing to this is that reduction of the machine length was found to be a common geometry adjustment as the pole number increased. This is because of the choice to maintain a constant terminal voltage, and a constant number of series turns per phase for all designs. The air gap voltage, the product of flux linkage and electrical frequency, was basically the same for all designs due to the choice to keep the terminal voltage at $690 \mathrm{~V}$. But, the electrical frequency rises directly with the number of poles. For an unchanging air gap voltage, the flux linkage must decrease as the frequency increases. If $N_{s}$ is held constant, and the geometry is not adjusted, the flux density deceases with increasing pole number. Since the diameter already had a constraint, adjustment of the length became the primary means of managing the flux density. The length of resulting designs ranges from 0.89 meters ( 30 poles) to 1.84 meters (4 poles). This also affected the efficiency, which is shown in Figure 7 to increase significantly as the pole number increases.

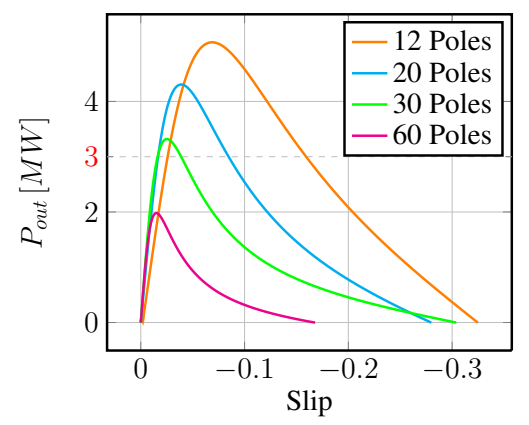

Fig. 5. Output power vs. slip for generators of several different pole numbers
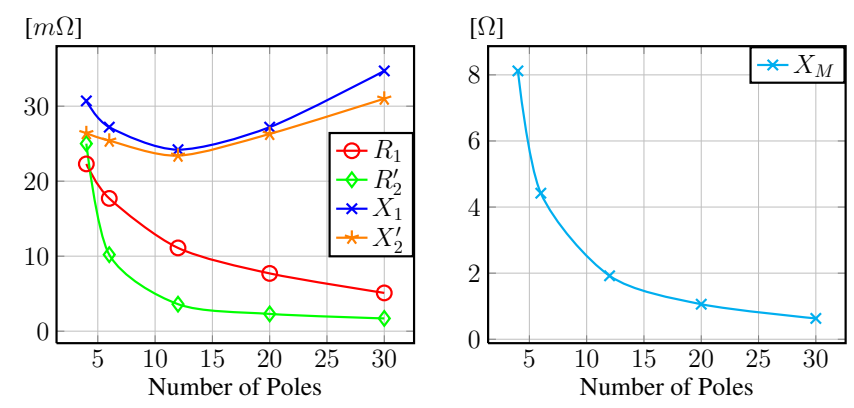

Fig. 6. Equivalent circuit parameters, as estimated for various pole numbers
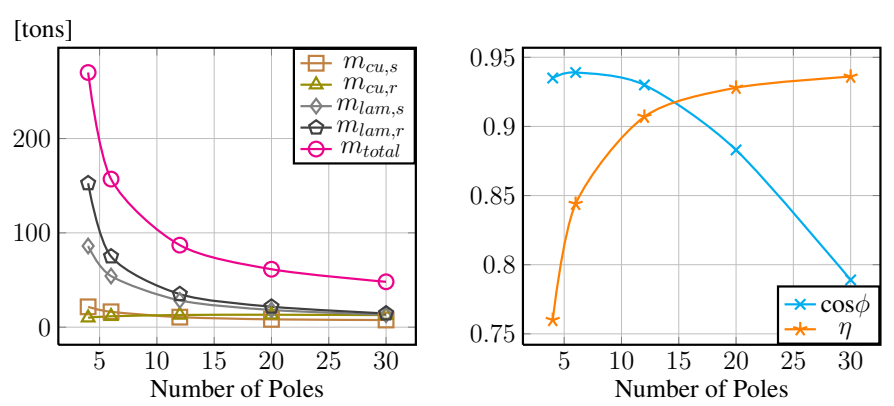

Fig. 7. Active mass, power factor, and efficiency for different pole numbers

On the other hand, the output power vs. slip characteristics of Figure 5 show that as the pole number increases, the peak output power decreases. This occurs because the leakage reactance increases with the number of poles. The height of the slip vs. output power characteristic is dependent on the leakage reactance, while the width is dependent on the stator and rotor resistances [12]. It can be seen that in the case of the 60 pole generator, the leakage reactance becomes prohibitively high under this particular set of design conditions. The methods used to estimate the leakage inductance have many dependencies (15-21). As the pole number rises, some contributing factors rise, while others fall. The result is that the leakage inductances don't trend so strongly with the pole number, given the restrictions of this study. It is clear, however, that the leakage reactances increase with the pole number, due to multiplication of the leakage inductance by the electrical frequency.

\section{B. Additional Example}

Given the results of the design process which has been undertaken, one may be led to question the possibility of further increasing the number of poles. To show that it is possible, one more design will be presented in which the previously-employed design restrictions are relaxed. A 60-pole generator has been designed analytically. Several adjustments were necessary for this design to be successful. The number of stator slots was increased to 360, giving two slots per pole per phase. A benefit of this increase in the number of slots, is that the number of conductors per slot can be reduced without so drastically reducing the series turns per phase. Reducing 
the number of conductors per slot is a very effective way to reduce slot leakage (15), however, for a given voltage it is also important for managing the flux density to keep the series turns high. These are competing factors, which must be balanced. In this case an increase in the number of slots helped to achieve this balance, but in the end it was still necessary to increase the length of the generator from 0.89 meters to 1.3 meters in order to keep the flux density at $0.9 \mathrm{~T}$. This increase in length has a counter-productive effect on the reduction in active mass which has been demonstrated in Figure 7. But, the required active mass for a 60 -pole generator is still estimated to be more than 5 tons lower than for a 30-pole generator. Table $\mathrm{V}$ gives the values of active mass, as well as the details of rated operation for the 50-pole generator. Aside from what is explicitly stated in Table $\mathrm{V}$, the restrictions of Table III are still applied.

TABLE V

DETAILS OF ADDITIONAL 3MW, 50-POLE GENERATOR

\begin{tabular}{llll}
\hline Parameter & Value & Parameter & Value \\
\hline$Q_{s}$ & 360 & slip & $1.42 \%$ \\
$Q_{r}$ & 420 & $\cos \phi$ & 0.689 \\
$z_{q}$ & 1 & $\eta$ & 0.944 \\
$R_{1}$ & $3.3 \mathrm{~m} \Omega$ & $m_{c u, s}$ & 5.5 tons \\
$R_{2}^{\prime}$ & $1.6 \mathrm{~m} \Omega$ & $m_{\text {cu }, r}$ & 8.7 tons \\
$X_{1}$ & $23.8 \mathrm{~m} \Omega$ & $m_{\text {lam }, s}$ & 14.5 tons \\
$X_{2}^{\prime}$ & $19.8 \mathrm{~m} \Omega$ & $m_{\text {lam }, r}$ & 14.3 tons \\
$X_{M}$ & $221.2 \mathrm{~m} \Omega$ & $m_{\text {tot }}$ & 43.0 tons \\
\hline
\end{tabular}

\section{FURTHER WORK}

Based on the knowledge gained from this study, the authors believe 60 poles to be a good starting point for a detailed design process. The required active mass is comparable to that of a 3MW electrically-excited direct-drive synchronous generator, but it remains more massive than a permanent magnet direct-drive generator of this rating [1]. Further work focused on optimization may allow the pole number to be further increased and the mass to be reduced. However, the power factor for a 60 -pole generator is estimated to be 0.689 , and it will become even lower as the pole number continues to rise. The expense of capacitors and power electronics for compensating the reactive power consumption of a direct-drive induction generator will rise as the power factor decreases, and this too must be considered. Conversely, the authors are aware that the thermal performance of IGBTs used in power converters is poor when the frequency is low, and this is another advantage of striving for a higher polarity.

This paper has focused on the active mass, but the structural mass required to maintain the air gap clearance is also of great significance for direct-drive wind turbine generators. This too must be considered in future work. The permanent magnet synchronous generators which are currently favored can have much higher pole numbers, leading to lower requirements of coreback thickness. But, the induction generator's higher coreback thickness also contributes toward maintenance of the air gap clearance [9], and from that perspective it is an advantage. The authors therefore hypothesize that a lower proportion of the overall mass of a direct-drive induction generator will be structural, when compared to a direct-drive synchronous generator.

\section{CONCLUSION}

The squirrel cage induction machine has been investigated for its use in direct-drive wind turbines. This paper notes several studies suggesting that the direct-drive wind turbines which are operating today have not exhibited increased reliability when compared to geared wind turbines. The simple design of the squirrel cage rotor may give increased reliability. In this paper, an initial electromagnetic design has been demonstrated. Calculations are based on a 3MW, $15 \mathrm{rpm}$ wind turbine, and it has been shown that choosing a high pole number reduces the required active mass, and also lowers the power factor. The leakage reactance increases with the pole number, with the effect that the pole number may not be increased arbitrarily. Despite working to increase the pole number, the required active mass remains high in comparison to permanent magnet generators. Nonetheless, giving caution to the future availability and prices of neodymium and dysprosium, the squirrel cage induction machine may become increasingly viable for this application.

\section{REFERENCES}

[1] H. Polinder, F. F. A. van der Pijl, G. J. de Vilder, and P. J. Tavner, "Comparison of direct-drive and geared generator concepts for wind turbines," IEEE Trans. Energy Convers., vol. 21, no. 3, pp 725-733, Sep. 2006.

[2] P. J. Tavner, G. J. W. V. Brussel, and F. Spinato, "Machine and converter reliabilities in wind turbines," Proc. 3rd Power Electron. Mach. Drives Conf. (PEMD 2006), Cork, Ireland, Mar., pp 127-130.

[3] E. Echavarria, B. Hahn, G. J. W. van Brussel, and T. Tomiyama, "Reliability of wind turbine technology through time," Trans. ASME (J. Sol. Eng.), vol. 130, no. 3, pp 0310051-0310058, Aug. 2008.

[4] D. McMillan and G. W. Ault, "Techno-economic comparison of operational aspects for direct drive and gearbox-driven wind turbines," IEEE Trans. Energy Convers., vol. 25, no. 1, pp 191-198, Mar. 2010.

[5] D. McMillan and G. W. Ault, "Condition monitoring benefit for wind turbines: Sensitivity to operational parameters," IET Renewable Power Generation, vol. 2, no. 1, pp 60-72, Mar. 2008.

[6] J. Lifton, "The effect of chinese domestic growth on neodymium and dysprosium supply," Technology Metals Research, 13 Mar. 2011, Retrieved 13 Mar. 2011, from http://www.techmetalsresearch.com/2010/08/theeffect-of-chinese-domestic-growth-on-neodymium-and-dysprosiumsupply/

[7] J. Lifton, "The rare earth crisis of 2009 - part 2: the green wind blows from china," Technology Metals Research, 8 Aug. 2009, Retrieved 3 Mar. 2011, from http://www.techmetalsresearch.com/2009/11/the-rareearth-crisis-of-2009-part-2-the-green-wind-blows-from-china/

[8] J. Lifton, G. Candy "The fight over rare earths," Technology Metals Research, 2 Nov. 2010, Retrieved 7 Mar. 2011, from http://www.techmetalsresearch.com/2010/08/the-fight-over-rare-earths/

[9] A.S. McDonald, M.A. Mueller, H. Pollinder, "Structural mass in directdrive permanent magnet electrical generators," IET Renew. Power Gener., vol. 2, no. 1, pp.3-15.

[10] A. Boglietti, A. Cavagnino, M. Lazzari, "Computational algorithms for induction motor equivalent circuit parameter determination part I: resistances and leakage reactances," IEEE Trans. Ind. Electron., Oct. 2010

[11] J. Pyrhönen, T. Jokinen, V. Hrabovcov, "Design of rotating electrical machines," West Sussex, UK, Wiley, 2008.

[12] P. L. Alger, "Induction Machines - Their Behavior and Uses," Gordon and Breach Science Publishers, 1970 